\title{
Association between Vitamin D Deficiency and Recurrent Acute Diarrhea in Children
}

Azza Ibrahim El- Desouky ${ }^{1}$, Mona Mohammed El Shaffi, ${ }^{1}$, Samar Mahmoud Sharaf ${ }^{2}$, Heba Ibrahim Salem Mohammed*1

${ }^{1}$ Department of Pediatrics, ${ }^{2}$ Department of Clinical Pathology, Faculty of Medicine, Zagazig University

*Corresponding author: Heba Ibrahim Salem Mohammed; Mobile: (+20)01151963676; E-mail: hebasalem184@gmail.com

\begin{abstract}
Background: Vitamin D deficiency is highly prevalent among children worldwide. It causes impairment of the immune response to infection and decreased activity of gut antimicrobial peptides. The impact of vitamin D deficiency on the severity of acute diarrhea among children may be helpful for diarrheal management.

Objective: To assess vitamin D deficiency and its correlation with recurrent acute diarrhea in children.

Subjects and Methods: This study included 60 children, (1 to 5 years old) suffering from recurrent acute diarrhea more than 6 times per last year. They were subjected to complete history, clinical examination laboratory investigation and supplementation of vitamin D for three months for children who had vitamin D deficiency or insufficiency. Results: Vitamin D deficiency was found in $56.7 \%$, insufficient in $21.7 \%$, and sufficient in $21.7 \%$ in children with recurrent acute diarrhea. There was a statistical difference as regards the number of acute diarrhea attacks and vitamin D deficiency. Hemoglobin level was decreased below normal in (55\%) of children with deficiency. Stool examination detected Enterobius vermicularis, Giardia lamblia, Entamoeba histolytica, and Ascaris lumbricoides in (26.7\%, $8.3 \%$ and $3.3 \%$, and $1.7 \%$ ) respectively. Seventy-five percent of the studied children were supplemented with vitamin $\mathrm{D}$ which significantly decreases the number of diarrheal attacks.

Conclusion: This study pay attention to the role of vitamin D in the susceptibility to infection-related illness in children. There is a positive correlation between vitamin D deficiency and iron-deficiency anemia. A significant decrease in the number of attacks of acute diarrhea after vitamin D supplementation was noted.
\end{abstract}

Keywords: Vitamin D, Recurrent Acute Diarrhea, Children.

\section{INTRODUCTION}

Diarrhea is defined as the passage of loose or watery stool than is normal for the child or increase in the frequency of stools for the child. It isn't a disease; it is a symptom for many diseases but its risk comes from being the second cause of death in children under five years. Each year diarrhea kills about 760,000 children under five years ${ }^{(\mathbf{1})}$.

Diarrhea may be acute which lasts less than two weeks and chronic which continues more than two or three weeks. Recurrent diarrhea is any large volume of stools or frequent loose stools that arise and resolve over and over again ${ }^{(2)}$.

Micronutrient deficiency may affect both innate cell-mediated immunity and adaptive antibody response and has shown to increase diarrhea-related morbidity and mortality ${ }^{(3)}$.

One of these micronutrients is vitamin D. It was proposed that there is an association between vitamin $\mathrm{D}$ deficiency and the current acute diarrhea. The interest has been grown over the last years about its role in nonskeletal medical conditions. The active metabolite of vitamin $\mathrm{D}$ is 1,25 dihydroxy vitamin $\mathrm{D}$ (calcitriol) which has an important role in regulating the immune response. It inhibits the proliferation of B cell and blocks its differentiation and immunoglobulin secretion ${ }^{(4)}$. It also suppresses the proliferation of $\mathrm{T}$ cells and inhibits dendritic cell differentiation and maturation ${ }^{(5)}$.

\section{AIM OF THE WORK}

Our study aims to assess vitamin D and find its correlation with recurrent acute diarrhea in children.

\section{SUBJECTS AND METHODS}

\section{1-Technical Design:}

- Type of the study: an interventional cross-sectional study.

- Study setting: The study was conducted on pediatric out Patient Clinics, Pediatric Department, Zagazig University Hospitals.

- Study period: May 2017 to November 2017.

- Sample size: 60 patients (31 males, 29 females) with recurrent acute diarrhea.

- Inclusion criteria: Children aged between 1-5 years old or with a history of recurrent acute diarrhea at least 6 attacks for one year.

- Exclusion criteria: Children with other causes of chronic diarrhea as malabsorption syndrome, celiac disease, ulcerative colitis, and chronic infection as T.B, children with history or signs and symptoms of rickets and severe malnutrition.

Patients were divided into three groups according to vitamin D level, vitamin D deficiency (level $<20$ $\mathrm{ng} / \mathrm{mL}$ ). Vitamin D insufficiency (level between 20 \& $30 \mathrm{ng} / \mathrm{mL}$ ). Vitamin D sufficiency (level $\geq 30$ $\mathrm{ng} / \mathrm{mL})^{(6)}$.

\section{2-Operational design:}

1- Complete history was taken from the parents of the children.

2- Family socioeconomic scale (SES): A modified form of Fahmi and El-Sherbini scale ${ }^{(7)}$ was used.

3- Full clinical examinations: Anthropometric measurements for BW, HT, and BMI. Vital signs $\mathrm{HR}$, BP, and RR. 
4- Systemic examination: to exclude the presence of any chronic illness.

5- Laboratory investigations: for hemoglobin concentration. Nutritional anemia is considered when the hemoglobin cut-off of $110 \mathrm{~g} / \mathrm{l}(11 \mathrm{~g} / \mathrm{dl})$ for children from 6-59 months of age ${ }^{(8)}$, stool analysis, serum 25 hydroxy vitamin D by Electrochemiluminescence binding assay ${ }^{(9)}$.

6- Vitamin D supplementation and follow up: For children with deficiency (34-child) and with insufficiency (13child).

\section{Ethical consideration:}

Approval of the study was obtained from Zagazig University academic and ethical committee. Every patient signed informed written consent for the acceptance of the study.

\section{Statistical Analysis}

The collected data were analyzed by computer using Statistical Package of Social Services version 22 (SPSS), Data were represented in tables and graphs, Continuous Quantitative variables e.g. age were expressed as the mean \pm SD \& median (range), and categorical qualitative variables were expressed as absolute frequencies (number) \& relative frequencies (percentage). Suitable statistical tests of significance were used after checked for normality. The results were considered statistically significant when the significant probability was less than $0.05(\mathrm{P}<0.05)$. P-value < 0.001 was considered highly statistically significant
(HS), and P-value $\geq 0.05$ was considered statistically insignificant (NS).

\section{RESULTS}

Table (1): Demographic data of the studied children $(\mathrm{n}=60)$.

\begin{tabular}{|l|c|c|}
\hline \multirow{2}{*}{ Demographic data } & \multicolumn{2}{c|}{$\begin{array}{c}\text { Studied children } \\
\text { (N=60) }\end{array}$} \\
\cline { 2 - 3 } & No. & $\%$ \\
\hline Age (years) & \multicolumn{2}{|c|}{$2.83 \pm 1.15$} \\
\hline$\bullet$ Mean \pm SD & \multicolumn{2}{|c|}{$3(1-5)$} \\
\hline$\bullet$ Median (Range) & 31 & 51.7 \\
\hline Sex & 29 & 48.3 \\
\hline$\bullet$ Male & 27 & 45.0 \\
\hline$\bullet$ Female & 21 & 35.0 \\
\hline Social class & 12 & 20.0 \\
\hline$\bullet$ Low & \multicolumn{3}{|c|}{} \\
\hline$\bullet$ Moderate & 40 & 66.7 \\
\hline High & 20 & 33.3 \\
\hline Residence & \multicolumn{3}{|c|}{} \\
\hline$\bullet$ Rural &
\end{tabular}

This table shows that the mean age of the studied group was $2.83 \pm 1.15$ years old, with a range from 1 to 5 years old. About half of the studied group were males, low social class constitutes $45 \%$. Also, $(66.7 \%)$ of cases were from rural areas.

Table (2): Correlation between vitamin D status and number of diarrheal attack per year, WT, HT, dehydration, and pallor among the studied children $(n=60)$.

\begin{tabular}{|c|c|c|c|c|c|c|c|c|}
\hline \multirow[b]{2}{*}{ Variable } & \multicolumn{6}{|c|}{ Vitamin D level } & \multirow[b]{2}{*}{ Test } & \multirow[b]{2}{*}{ P-value } \\
\hline & \multicolumn{2}{|c|}{ Deficient $N=(34)$} & \multicolumn{2}{|c|}{$\begin{array}{r}\text { Insufficient } \\
\qquad=(13)\end{array}$} & \multicolumn{2}{|c|}{ Sufficient $(\mathrm{N}=(\mathbf{1 3})$} & & \\
\hline \multicolumn{7}{|c|}{ Number of attack acute diarrhea in the last year } & KWT & P-value \\
\hline Mean $\pm \mathrm{SD}$ & \multirow{2}{*}{\multicolumn{2}{|c|}{$\begin{array}{l}7.5 \pm 1.46 \\
7(6-10)\end{array}$}} & \multirow{2}{*}{\multicolumn{2}{|c|}{$\begin{array}{c}7 \pm 1.08 \\
7(6-10)\end{array}$}} & \multirow{2}{*}{\multicolumn{2}{|c|}{$\begin{array}{c}6.38 \pm 0.76 \\
6(6-8)\end{array}$}} & \multirow{2}{*}{ \#6.832 } & \multirow{2}{*}{$\begin{array}{c}0.033 \\
(\mathrm{~S})\end{array}$} \\
\hline \multirow[t]{2}{*}{ Median (Range) } & & & & & & & & \\
\hline & No & $\%$ & No & $\%$ & No & $\%$ & Chi-square & P-value \\
\hline \multicolumn{9}{|l|}{ Weight } \\
\hline Underweight & 4 & 11.8 & 2 & 15.4 & 1 & 7.7 & \multirow{2}{*}{0.374} & 0.829 \\
\hline Normal & 30 & 88.2 & 11 & 84.6 & 12 & 92.3 & & $(\mathrm{NS})$ \\
\hline \multicolumn{9}{|l|}{ Height } \\
\hline Short for age & 1 & 2.9 & 1 & 7.7 & 0 & 0.0 & \multirow{2}{*}{1.231} & 0.540 \\
\hline Normal & 33 & 97.1 & 12 & 92.3 & 13 & 100.0 & & $(\mathrm{NS})$ \\
\hline \multicolumn{9}{|l|}{ Dehydration } \\
\hline Positive & 7 & 20.6 & 2 & 15.4 & 2 & 15.4 & \multirow{2}{*}{0.266} & 0.875 \\
\hline Negative & 27 & 79.4 & 11 & 84.6 & 11 & 84.6 & & $(\mathrm{NS})$ \\
\hline \multicolumn{9}{|l|}{ Pallor } \\
\hline Positive & 12 & 35.3 & 5 & 38.5 & 4 & 30.8 & \multirow{2}{*}{0.172} & \multirow{2}{*}{$\begin{array}{l}0.918 \\
(\mathrm{NS})\end{array}$} \\
\hline Negative & 22 & 64.7 & 8 & 61.5 & 9 & 69.2 & & \\
\hline
\end{tabular}

\# Kruskal Wallis Test Chi-square test $\quad \mathrm{P}<0.05$ is significant.

This table shows that there was no statistically significant difference between vitamin D status and weight, height, dehydration and even pallor, but there was a statistical significant difference in the mean of the number of acute diarrheal attacks as it was higher in vitamin deficiency than that in the insufficient group $(7.5 \pm 1.46$ and $6.38 \pm 0.76)$ respectively. 
Table (3): Correlation between laboratory investigations and vitamin D status among the studied children $(\mathrm{N}=60)$.

\begin{tabular}{|c|c|c|c|c|c|c|c|c|}
\hline \multirow{3}{*}{ Variable } & \multicolumn{6}{|c|}{ Vitamin D level } & \multirow{3}{*}{$\begin{array}{l}\text { Chi- } \\
\text { square } \\
\text { test }\end{array}$} & \multirow{3}{*}{ P-value } \\
\hline & \multicolumn{2}{|c|}{$\begin{array}{c}\text { Deficient } \\
\mathrm{N}=(\mathbf{3 4})\end{array}$} & \multicolumn{2}{|c|}{$\begin{array}{c}\text { Insufficient } \\
\mathbf{N}=(\mathbf{1 3})\end{array}$} & \multicolumn{2}{|c|}{$\begin{array}{c}\text { Sufficient } \\
N=(13)\end{array}$} & & \\
\hline & No & $\%$ & No & $\%$ & No & $\%$ & & \\
\hline \multicolumn{9}{|c|}{ Hemoglobin level } \\
\hline Low & 23 & 67.6 & 3 & 23.1 & 7 & 53.8 & \multirow{2}{*}{7.557} & \multirow{2}{*}{$\begin{array}{c}0.023 * \\
(\mathrm{~S})\end{array}$} \\
\hline Normal & 11 & 32.4 & 10 & 76.9 & 6 & 46.2 & & \\
\hline \multicolumn{9}{|c|}{ Stool analysis } \\
\hline Normal & 15 & 44.1 & 11 & 8.6 & 10 & 76.9 & 8.407 & 0.014* \\
\hline Oxyuris & 13 & 38.2 & 2 & 15.4 & 1 & 7.7 & 5.566 & 0.061 \\
\hline Giardia & 4 & 11.8 & 0 & 0.0 & 1 & 7.7 & 1.713 & 0.424 \\
\hline E.histolytica & 1 & 2.9 & 0 & 0.0 & 1 & 7.7 & 1.231 & 0.540 \\
\hline Ascaris & 1 & 2.9 & 0 & 0.0 & 0 & 0.0 & 0.777 & 0.677 \\
\hline
\end{tabular}

$\mathrm{P}<0.05$ is significant.

This table shows that a low level of hemoglobin is higher with vit.D deficiency than sufficient group (67.6\% and 53.8\%) respectively with a significant difference. Normal stool analysis was much higher in children with sufficient vit. D level that patient with vit. D deficiency (76.9\%, and $44.1 \%)$ respectively.

Table (4): Correlation between vitamin D level and HB, weight, height, number of diarrheal attacks among the studied children.

\begin{tabular}{|l|c|c|}
\hline \multirow{2}{*}{ Item } & \multicolumn{2}{|c|}{ Vitamin D level } \\
\cline { 2 - 3 } & Correlation coefficient (r) & p- value \\
\hline Hemoglobin & 0.226 & $0.082(\mathrm{NS})$ \\
\hline Weight & 0.058 & $0.657(\mathrm{NS})$ \\
\hline Height & -0.035 & $0.792(\mathrm{NS})$ \\
\hline number of diarrheal attacks & $\mathbf{- 0 . 2 5 6}$ & $\mathbf{0 . 0 4 8}$ (S) \\
\hline
\end{tabular}

*Correlation is significant at the 0.05 level.

This table shows that there is a significant negative correlation between vitamin $\mathrm{D}$ level and the number of diarrheal attacks ( $\mathrm{r}=-0.256$, P-value $>0.05)$ when vitamin $\mathrm{D}$ level is increased, the number of diarrheal attacks decreased.

Table (5): Correlation between sun exposure and history of vitamin D supply and vitamin D status among the studied children $(\mathbf{N}=60)$.

\begin{tabular}{|c|c|c|c|c|c|c|c|c|}
\hline \multirow{3}{*}{ Variable } & \multicolumn{6}{|c|}{ Vitamin D level } & \multirow{3}{*}{$\begin{array}{l}\text { Chi- } \\
\text { square } \\
\text { test }\end{array}$} & \multirow{3}{*}{$\begin{array}{c}\text { P- } \\
\text { value }\end{array}$} \\
\hline & \multicolumn{2}{|c|}{$\begin{array}{c}\text { Deficient } \\
\mathbf{N}=(\mathbf{3 4})\end{array}$} & \multicolumn{2}{|c|}{$\begin{array}{c}\text { Insufficient } \\
\mathbf{N}=(\mathbf{1 3})\end{array}$} & \multicolumn{2}{|c|}{$\begin{array}{c}\text { Sufficient } \\
\mathbf{N}=(\mathbf{1 3})\end{array}$} & & \\
\hline & No & $\%$ & No & $\%$ & No & $\%$ & & \\
\hline \multicolumn{9}{|l|}{ Sun exposure } \\
\hline Positive & 5 & 14.7 & 10 & 76.9 & 11 & 84.6 & \multirow{2}{*}{26.34} & \multirow{2}{*}{$\begin{array}{c}0.000^{*} \\
(\mathrm{HS})\end{array}$} \\
\hline Negative & 29 & 85.3 & 3 & 23.1 & 2 & 15.4 & & \\
\hline \multicolumn{9}{|c|}{ History of vitamin D supply } \\
\hline Positive & 11 & 32.4 & 8 & 61.5 & 10 & 76.9 & \multirow{2}{*}{8.64} & \multirow{2}{*}{$\begin{array}{c}0.013 \\
(\mathrm{~S})\end{array}$} \\
\hline Negative & 23 & 67.6 & 5 & 38.5 & 3 & 23.1 & & \\
\hline
\end{tabular}

$\mathrm{P}<0.05$ is significant.

This table shows that, among vitamin D deficient group (34), 23 children had no history of vitamin D supply, with statistically significant difference ( $\mathrm{p}<0.05)$, five children have a history of proper exposure to sun and 29 have a history of improper exposure to the sun, with high statistical significance. 
Table (6): Number of acute diarrheal attacks within 3 months after vitamin D supplementation among the studied children $(\mathbf{N}=\mathbf{4 5})$.

\begin{tabular}{||l|c|c|}
\hline \multicolumn{1}{|c|}{ Item } & \multicolumn{2}{c|}{ Studied children (N=45) } \\
\cline { 2 - 3 } & \multicolumn{2}{c|}{ No. } \\
\hline Number of diarrheal attacks within 3 months of treatment \\
\hline Mean \pm SD & \multicolumn{2}{c|}{$1.31 \pm 0.92$} \\
\hline Median (Range) & \multicolumn{3}{c|}{} \\
\hline No of attacks after vitamin D & 10 & 22.2 \\
\hline No attack & 15 & 33.3 \\
\hline Once & 16 & 35.6 \\
\hline Twice & 4 & 8.9 \\
\hline 3 times & & \\
\hline
\end{tabular}

This table shows that the mean number of acute diarrheal attacks during 3 months under vitamin D supplementation was $1.31 \pm 0.92$ times, with a range from 0 to 3 times. Most of the studied group had no attacks, once or twice $(22.2 \%, 33.3 \%$, and $35.6 \%)$ respectively, only $8.9 \%$ of them suffered from acute diarrheal attacks 3 times (35\%), with 2 cases dropped from the study.

Table (7): Number of acute diarrheal attacks before and within 3 months after vitamin $D$ supplementation among the studied children $(\mathrm{N}=45)$.

\begin{tabular}{||c|c|c|c|c|}
\hline $\begin{array}{c}\text { Number of diarrheal } \\
\text { attacks }\end{array}$ & $\begin{array}{c}\text { Before vitamin D } \\
\text { per 3 months }\end{array}$ & $\begin{array}{c}\text { After vitamin D } \\
\text { within 3 months }\end{array}$ & Test & P-value \\
\hline Mean \pm SD & $3.1 \pm 0.98$ & $1.31 \pm 0.92$ & -2.882 & $0.000^{*}$ \\
Median (Range) & $4(2-4)$ & $1(0-3)$ & HS $)$ \\
\hline
\end{tabular}

Wilcoxon Signed Ranks Test

$\mathrm{P}<0.05$ is significant.

The above table shows that the mean number of acute diarrheal attacks among the studied children within 3 months before vitamin D supplementation decreased from $(3.1 \pm 0.98)$ times to $(1.31 \pm 0.92)$ times within 3 months with supplementation with a highly statistically significant difference.

\section{DISCUSSION}

Vitamin D deficiency is a major public health problem worldwide in all age groups. The consequences of vitamin D deficiency extend beyond its well-known effects on bone metabolism and calcium homeostasis and also include alterations of specific arms of immunity. The immunomodulatory properties of vitamin D may influence susceptibility to infection ${ }^{(10)}$.

This study was done to find the association between vitamin $\mathrm{D}$ deficiency and recurrent acute diarrhea in children aged 1 to 5 years old, where 60 children were studied and divided according to their serum level of vitamin D into vitamin D insufficiency level between 20 and $30 \mathrm{ng} / \mathrm{mL}$ (50 to $75 \mathrm{nmol} / \mathrm{L}$ ), vitamin $\mathrm{D}$ deficiency level below $20 \mathrm{ng} / \mathrm{mL}$ (50 $\mathrm{nmol} / \mathrm{L})$, vitamin $\mathrm{D}$ sufficiency $\geq 30 \mathrm{ng} / \mathrm{mL}$ (75 $\mathrm{nmol} / \mathrm{L})$.

In this study, vitamin D was deficient in 34 patients $(56.7 \%)$, insufficient in $13(21.7 \%)$, sufficient in $13(21.7 \%)$ in children with recurrent acute diarrhea with a highly significant difference. In agreement with our result, Mileva et al. ${ }^{(11)}$ study in toddlers with acute diarrhea had vitamin D insufficiency.

There was also no substantial difference in both sex and no age limited behavior for vitamin D deficiency. Dyląg et al. ${ }^{(12)}$ agreed with our data where there was a high prevalence rate of vitamin D deficiency in children aged 1-5 years old, with no sex difference. Roh et al. ${ }^{\left({ }^{(13)}\right.}$ and Basatemur et al. ${ }^{(14)}$, disagreed with us because of differences between them and our study in the target age group and place of the study.

In our study, most cases of vitamin D deficiency were from rural areas $(85.3 \%-29)$ and most of them were of low social class (55.9 \% -19). This may be related to maternal education, socioeconomic status, and vitamin supply behavior. This agreed with AlHorani et al. ${ }^{(15)}$, in which socioeconomic deprivation was associated with higher rates of vitamin D deficiency.

In our study, there was no statistical difference between vitamin D status and weight and height. Thornton et al. ${ }^{(16)}$ agreed with our data, in a study of Vitamin D deficiency associated with an increased incidence of gastrointestinal and ear infections in school-age children, and detected that there was no difference in weight and height between vitamin D deficient and sufficient groups.

While Gilbert-Diamond et $\boldsymbol{a l} .{ }^{(17)}$, reported that vitamin D deficiency was related to slower liner growth 
in female children rather than male children, and their results suggested that inadequate vitamin D status may prospectively lead to increased adiposity during childhood.

Many studies disagreed with us and linked between vitamin $\mathrm{D}$ deficiency and overweight in children as in Wakayo et al. ${ }^{(18)}$. The study founded that Vitamin D deficient children had statistically significantly higher BMI than children with normal vitamin D status. Nam et al. ${ }^{(19)}$ found that vitamin D deficient $(25(\mathrm{OH}) \mathrm{D}$ level $<50 \mathrm{nmol} / \mathrm{L})$ was associated with a higher risk for overweight or obesity. The difference in age group and site of the study may be the cause of differences in results between our study and other studies.

Our study revealed that about $67.6 \%$ (23) of vitamin $\mathrm{D}$ deficient children had decreased hemoglobin levels below normal. A significant correlation between low serum vitamin D and iron deficiency anemia was founded in these patients. This may be due to decreased vitamin $\mathrm{D}$ absorption following impairment of intestinal fat absorption due to iron deficiency or controversy, induction of anemia due to increased inflammation and rate of infection due to impaired immunity and gastrointestinal tract function due to vitamin D deficiency. Liu et al. ${ }^{(20)}$ agreed with our data and found that individuals with Vit D deficiency associated with a $64 \%$ increased risk of anemia. Also, Yoon et al. (21) demonstrated that vitamin D deficiency has a high prevalence in Korean children with iron deficiency anemia.

Nemeth and Ganz (22) supported us and suggested that vitamin D may support erythropoiesis through regulating pro-inflammatory cytokines and hepcidin, vitamin D may, therefore, improve anemia, in particular, anemia of inflammation.

Laboratory investigations were done for our included cases stool analysis revealed that Enterobius vermicularis was founded in a higher percentage than Giardia lamblia, or E. histolytica $(26.7 \%, 8.3 \%$, and $3.3 \%$ ) respectively, only 1.7 for Ascaris infection.

Worldwide, approximately more than 2 billion people are infected with helminths infection. In Africa, more than 173 million people are infected with Ascaris lumbricoides, more than 162 million cases of trichuriasis, and more than 198 million cases of hookworm. In developing countries $12 \%$ of the global disease burdens due to intestinal worms were estimated to occur on children 5-14 years old ${ }^{(23)}$.

Among our vitamin D deficient children $67.6 \%$ had no history of vitamin D supply, which was statistically significant and in proper exposure to sunlight $85.3 \%$ with a significant difference. Shady $\boldsymbol{e t}$ al. ${ }^{(24)}$ supported our data and showed that children with low physical activity, limited sun exposure and children with milk intake less than once/day had statistically significant lower serum $25(\mathrm{OH}) \mathrm{D}$ than their peers. Also
Mandlik et al. ${ }^{(25)}$ in school-children aged 6-12 years, from a semirural setting, despite a majority (80\%) reporting $>2 \mathrm{~h}$ of sunlight exposure. The difference may be due to excessive exposure to sunlight cause destruction of vitamin $\mathrm{D}$.

In our study, $75 \%$ of the studied children were supplemented with vitamin D and $25 \%$ were of no need for vitamin D supplementation. The group received vitamin $\mathrm{D}$ showed actual improvement in diarrheal attacks, the mean number of acute diarrheal attacks among the studied children decreased from $(7.15 \pm 1.32)$ before vitamin $\mathrm{D}$ supplementation to $(1.31 \pm 0.92)$ after 3 months of vitamin D supplementation in a dose of 600 IU/day of V- drop preparation of( vitamin D3 ) with a high statistical difference.

Yakoob et al. ${ }^{(26)}$ were against us. They showed that there was no obvious difference in the first or repeat episodes of diarrhea between supplemented and nonsupplemented children.

Vitamin D regimen and study length may be the cause of the difference between the results of our study and this study.

\section{CONCLUSION}

There is a significant correlation between low serum vitamin $\mathrm{D}$ and recurrent acute diarrhea in children, suggesting several explanations for this relationship, including decreased vitamin $\mathrm{D}$ absorption following impairment of intestinal fat absorption or controversy, induction of many diarrheal episodes due to impaired immunity and impaired mucosal barrier integrity.

\section{REFERENCES}

1. Kirk MD, Pires SM, Black RE et al. (2015): World Health Organization Estimates of the Global and Regional Disease Burden of 22 Foodborne Bacterial, Protozoal, and Viral Diseases, A Data Synthesis. PLoS Med., 12(12):121.

2. Chris E (2015): Recurrent Diarrhea-Causes of Repeated Bouts of Diarrhea. Available at https://www.healthhype.com/recurrent-diarrhea-causesof-repeated-bouts-of-diarrhea.html.

3. Wintergerst ES, Maggini S, Hornig DH (2007): Contribution of selected vitamins and trace elements to immune function. Ann Nutr Metab., 51(4):301-23.

4. Chen S, Sims GP, Chen XX et al. (2007): Modulatory effects of 1, 25-dihydroxy vitamin D3 on human B cell differentiation. J Immun., 179(3):1634-47.

5. Széles L, Keresztes G, Töröcsik D et al. (2009): 1, 25dihydroxy vitamin D3 is an autonomous regulator of the transcriptional changes leading to a tolerogenic dendritic cell phenotype. J Immunol., 182(4):2074-83.

6. Matthias W, Michael FH (2013): Vitamin D Effects on Skeletal and Extraskeletal Health and the Need for Supplementation. Nutrients, 5(1): 111-148.

7. Fahmy SI, EL-Sherbini AF (1983): Determining simple parameters for social classification for health. The Bulletin of HIPH. Alex., V111 (5): 95-100. 
8. WHO (2017): Nutritional Anaemias: Tools for Effective Prevention. World Heal Organ. Available at: https://www.who.int/nutrition/ publications/micronutrients/ anaemias- tools -preventioncontrol/en/.

9. Holick MF (2009): Vitamin D status: measurement, interpretation, and clinical application. Ann Epidemiol., 19(2):73-78.

10. Palacios C, Gonzalez L (2014): Is vitamin D deficiency a major global public health problem?. J Steroid Biochem Mol Biol., 144:138-45.

11. Mileva S, Galunska B, Gospodinova M et al. (2014): Vitamin D3 status in children with acute diarrhea. Integr Food Nutr Metab., 1(2):1-6.

12. Dyląg H, Rowicka G, Strucińska M et al. (2014): Assessment of vitamin D status in children aged 1-5 with simple obesity. Rocz Państwowego Zakładu Hig., 65(4):325-330.

13. Roh YE, Kim BR, Choi WB et al. (2016): Vitamin D deficiency in children aged 6 to 12 years: Single center's experience in Busan. Ann Pediatr Endocrinol Metab., 21(3):149-154.

14. Basatemur E, Horsfall L, Marston L et al. (2017): Trends in the diagnosis of Vitamin D deficiency. Pediatrics, 139(3): e20162748.

15. Al-Horani H, Abu Dayyih W, Mallah E et al. (2016): Nationality, gender, age, and body mass index influences on Vitamin D concentration among elderly patients and young Iraqi and Jordanian in Jordan. https://www.ncbi.nlm.nih.gov/pmc/articles/PMC482350 3/

16. Thornton KA, Marín C, Mora-Plazas M et al. (2013): Vitamin D deficiency associated with an increased incidence of gastrointestinal and ear infections in schoolage children. Pediatr Infect Dis J., 6: 585-593.
17. Gilbert-Diamond D, Baylin A, Mora-Plazas M et al. (2010): Vitamin D deficiency and anthropometric indicators of adiposity in school-age children: A prospective study. Am J Clin Nutr., 92(6):1446-1451.

18. Wakayo T, Whiting SJ, Belachew T (2016): Vitamin D deficiency is associated with overweight and/or obesity among schoolchildren in central Ethiopia: A crosssectional study. Nutrients, 8(4): 190-196.

19. Nam GE, Kim DH, Cho KH et al. (2014): 25Hydroxyvitamin D insufficiency is associated with cardiometabolic risk in Korean adolescents: the 20082009 Korea National Health and Nutrition Examination Survey (KNHANES). Public Health Nutr., 17(1):186-94.

20. Liu T, Zhong S, Liu L et al. (2015): Vitamin D deficiency and the risk of anemia: a meta-analysis of observational studies. Renal Failure, 37(6):929-34.

21. Yoon JW, Kim SW, Yoo EG et al. (2012): Prevalence and risk factors for vitamin D deficiency in children with iron deficiency anemia. Korean J. Pediatr., 55(6):206-209.

22. Nemeth E, Ganz T (2019): Anemia of inflammation. N Engl J Med., 381(12):1148-1157.

23. WHO (2010): First WHO report on neglected tropical diseases: working to overcome the global impact of neglected tropical diseases. whqlibdoc.who.int > 2010 > 9789241564090_eng

24. Shady MM, Youssef MM, Shehata MA et al. (2015): Association of serum 25-hydroxyvitamin D with lifestyle and dietary factors in Egyptian prepubescent children. Open Access Maced J Med Sci., 3(1):80-84.

25. Mandlik R, Kajale N, Ekbote $\mathrm{V}$ et al. (2018): Determinants of Vitamin D status in Indian schoolchildren. Indian J Endocrinol Metab., 22(2):244-246.

26. Yakoob MY, Salam RA, Khan FR et al. (2016): Vitamin D supplementation for preventing infections in children under five years of age. Cochrane Database Syst. Rev., 11:CD008824. 